\title{
Understanding the Last Days of Life: Information and Resources for Patients and Family Members
}

Author

Penny Glassman, Head Technology Initiatives, Lamar Soutter Library, University of Massachusetts Medical School, 55 Lake Avenue North, Worcester, MA 01655. Email: penny.glassman@umassmed.edu.

\section{Abstract}

The purpose of this article is to describe my experience during the last few days of my father's life. My father had been suffering with dementia for approximately eight years. As a family, we worked together to plan his care. However, we were not prepared for his last days of life. Understanding the process helped me cope with the end of my father's life. The end of the article includes links to some freely available resources to help you, your family, and your patrons.

\section{Key Words}

advance care planning, dementia, end-of-life, hospice care, last hours of life

All of us will die. For the overwhelming majority of us, our death will be a process. Only about $10 \%$ of us die suddenly ("Our Goal in Endlink"). During our last days and hours of our life, hopefully our loved ones will be near and they will observe our bodies going through a somewhat predictable process.

My father had been suffering with dementia for approximately eight years. He lived in a long-term care facility during the last year of his life. As a family, we worked together to plan his care. However, we were not prepared for his last days of life. Since I am a health science librarian, my instinct was to talk to his health care providers and look for resources to understand the process of the body shutting down. Understanding the process helped me cope with the end of my father's life. I doubt most people will run to the library during a loved one's last hours of life. However, consider including some of the links at the end of the article in other end-of-life planning information you make available to patrons.

\section{Advanced Care Planning}

There is a great deal of information available about the importance of end-of life planning. An increasing number of families are having conversations with loved ones about their wishes at the end-of-life.

Advanced Care Planning involves deciding who will make health decisions and what decisions should be made ("Conversation Project"). For example:

- Is there a preference to die at home, a hospice, or medical facility?

- What are the preferred treatment options at the end of life?

- Are there any requests for the funeral?

- Is there a preferred funeral home?

This is an Author's Accepted Manuscript of an Article published in Journal of Consumer Health on the Internet, June 4, 2014 and available online at: http://www.tandfonline.com/10.1080/15398285.2014.902285 ." 
These are difficult but important conversations to have with family, friends, and the patient's health care team. Using the answers to these questions, people are advised to prepare Advance Directives, including a Heath Care Power of Attorney so family members and the medical team understand the desires of the patient. However, even when these decisions are discussed and outlined in writing, the last months, days, and hours of life are very stressful and emotional for the patient and family.

\section{Hospice Care}

My father had been suffering from a form a dementia for about eight years. For the last year he was living in a long-term care facility. After about seven months in the facility, he was diagnosed with Acute Myeloid Leukemia (AML). Even with aggressive treatment, the prognosis for seniors with AML is very poor. Therefore, the family decided not to treat the AML. We knew my father only had two to six months of life, but we felt it was better than aggressive treatment of the AML with a very small chance of remission.

This is when my father began hospice care at the facility. The focus of hospice is caring for the patient and family, not curing the disease. For the example, the goal is making the patient comfortable by treating pain. The hospice care team also provides emotional and spiritual support to patients and their families. The team brought in a CD player so my father could listen to familiar music, and they removed most of his medications, except the ones needed to relieve pain and discomfort. My brother, mother, and $I$ also received support from the team, and our support continued for a year after his death.

\section{The Last Days and Hours of Life}

Before the experience with my father, I knew health care professionals notified family members of the approaching death of a loved one. It never occurred to me to investigate how they knew. Through my research, I learned that our bodies go through a somewhat predictable process as it approaches death. The initial symptoms may be subtle. For example, the person may begin to withdraw from people and have very little to say. They may also seem confused or show little interest in their surroundings. Some talk about leaving or taking a trip. Some talk to friends who have already passed away, either to absolve the friend of a wrongdoing or because they see a vision of the person. They also tend to eat and drink less, saying they are not hungry. In addition, they may be very tired, sleep most of the day, and have problems swallowing.

It was a Tuesday evening, May 29, 2012, when I received the call, I was expecting from my mother. There was not much time left and I needed to make the trip to New Jersey. I threw a closet full of clothes into my car and made the five-hour drive. When I arrived at the long-term care facility and kissed my father, it was the last time I saw him open his eyes.

Based on my research, I discovered that as a person approaches the last days or hours of life, the body goes through a number of changes in:

- Body function

- Consciousness

- Secretions

This is an Author's Accepted Manuscript of an Article published in Journal of Consumer Health on the Internet, June 4, 2014 and available online at: http://www.tandfonline.com/10.1080/15398285.2014.902285 ." 
- Circulation and temperature

- Breathing

\section{Body Function}

As a person nears death, he or she will experience profound weakness and fatigue, for example, the person may not have the strength to get out of bed. Since the body no longer needs fuel to keep going, there is no longer a desire for food or drink. We were told that it is important not to force food or drink. It was suggested we give my father ice chips or moisten his mouth with a damp cloth. Forcing food and fluids can make the patient uncomfortable or cause choking.

One thing I found rather disturbing was the movement of my father's arms in the air. I was concerned that he was in pain or it was a reaction to a medication he was taking. This is the point when the librarian in me kicked in and I started looking for resources to understand the dying process. It turns out, muscle "jerking and twitching" sometimes occurs during the last days of life.

\section{Consciousness}

As I mentioned, the last time I saw my father open his eyes was when I arrived at his bedside. My mother, brother, and I would sit next to him, talk to him, and massage his hands and arms. Sometimes he would squeeze our hand. We never knew if it was part of the "muscle jerking and twitching", or if he actually heard us. We like to think that he was responding to hearing us.

\section{Secretions}

The body is taking in less food and fluids, and there is a reduction in urine and bowel movements. Since the kidneys are shutting down, the urine becomes concentrated and may be dark in color.

\section{Circulation and Temperature}

The heart, lungs, and circulation are also slowing down. My father's hands, arms, feet, and legs felt cool. In addition, as death approaches, the skin may turn blue around the nose, mouth, fingers, and toes.

\section{Breathing}

The person's breathing may become labored or gurgling. The gurgling is caused by fluid pooling in the back of the throat due to problems with swallowing. This is often called the "death rattle." The person may also experience changes in the pattern of breathing. For example, he or she may have long periods without breathing followed by several quick, deep breaths. The heart rate and blood pressure may go down and become irregular.

\section{End of Life}

On the Friday night of that week I was alone with my father. I said the Shema, a Jewish prayer said twice a day and often said before dying. I told him it was alright to "let go" and kissed him good-bye. My brother stayed with him during the night. They are both big basketball fans. My brother turned on the television to a basketball playoff game between the Miami Heat and the Boston Celtics, hoping my father would be able to hear the game. They always rooted against the Celtics, but that night Boston won. My father died during the night.

This is an Author's Accepted Manuscript of an Article published in Journal of Consumer Health on the Internet, June 4, 2014 and available online at: http://www.tandfonline.com/10.1080/15398285.2014.902285 ." 
My brother and mother planned the funeral ahead of time and alerted the funeral home earlier in the week. My brother knew what to do upon my father's death. The preplanning made a difficult day a little easier.

\section{Some Closing Thoughts}

The approaching death a love one is a stressful time for every family. To help reduce some of the stress, we should have conversations with our loved ones about our own desires for end-of-life care and discuss the care our family members want at the end of their life. We should work with family members to prepare Advance Directives, including a Heath Care Power of Attorney so others understand our desires and who is responsible for making treatment decisions. Check the AARP: Advance Directives Forms by State ("Free Printable Advanced Directives Forms") or a similar web site to learn about the requirements in your state. These are not easy conversations. To start the planning process, I strongly recommend reviewing the information on The Conversation Project web site, including the Starter Kit ("Conversation Project").

If you or a family member is nearing the end-of-life, take advantage of hospice care that is often available either in your home, a skilled nursing facility, a hospital, or a hospice facility. Hospice care is provided by a team of doctors, nurses, social workers, spiritual counselors, and volunteers who treat the pain and medical needs of the patient, and also provide emotional and spiritual support for patients and families.

I also recommend making the funeral arrangements ahead of time so you do not need to make these difficult decisions after the death of a loved one. Even if you do not make the complete arrangements, it is best to select a funeral home in advance, confirm burial information with the cemetery or purchase a plot if you have not done so already, and have a discussion with the funeral director to understand the procedures after your loved one dies. Also make sure you communicate the desired funeral home and procedures to family and friends who may be around during the last hours of life.

If you or your loved one is religious, you may want to contact a priest, rabbi, minister, or imam during the last days of life. In each tradition there is a last rite that is given by a religious leader. Most of these prayers are said while the person is still alive. It is best to notify the religious leader as the family begins to gather to insure there is enough time for the religious leader to see your loved one before death. It is also an opportunity to notify the religious leader if you would like them to be involved with the funeral service.

We do not want to think about death. It seems strange to plan for death. But death is something each of us will experience. I hope this article helps you plan as peaceful a death as possible for you and your family members.

This is an Author's Accepted Manuscript of an Article published in Journal of Consumer Health on the Internet, June 4, 2014 and available online at: http://www.tandfonline.com/10.1080/15398285.2014.902285 ." 


\section{Acknowledgements}

Comments and suggestions should be sent to the Column Editors: Mary E. Nolan

(hospitallibrarian@yahoo.com) and Amy Knehans (aknehans@hmc.psu.edu).

\section{Selected Internet Resources}

AARP Caregiver Resource Center. n.d. End of life. http://www.aarp.org/home-family/caregiving/end-oflife.html(accessed December 12, 2013)

AARP . 2012 . Free printable advanced directives

forms http://www.aarp.org/relationships/caregiving/info-03-2012/free-printable-advance-

directives.html (accessed December 12, 2013)

American Cancer Society. n.d. Nearing the end of life.

http://www.cancer.org/treatment/nearingtheendoflife/nearingtheendoflife/nearing-the-end-of-lifetoc (accessed December 13, 2013)

Endlink: Resource for end of life care in America. n.d. Our goal in Endlink.

http://endlink.lurie.northwestern.edu/introduction/what.cfm (accessed December 12, 2013)

Fox Chase Cancer Center. n.d. Last hours of life.

http://www.fccc.edu/cancer/pdq/English/Patients/LastHoursofLife.html (accessed December 13, 2013)

Hospice Foundation of America. n.d. What to expect before death. http://www.hospicefoundation.org/beforedeath. (accessed December 13, 2013)

Institute for Healthcare Improvement. n.d. The conversation

project. http://theconversationproject.org/starter-kit/intro/ (accessed December 12, 2013)

Kokua Mau: Hawaii's hospice and palliative care organization. n.d. The last stages of life. http://kokuamau.org/resources/last-stages-life (accessed December 13, 2013)

Mayo Clinic . 2011 . End of life: Caring for a dying loved one http://www.mayoclinic.com/print/cancer/CA00048/METHOD=print (accessed December 13, 2013)

MedlinePlus . 2013 . End of life issues

http://www.nlm.nih.gov/medlineplus/endoflifeissues.html (accessed December 12, 2013)

MedlinePlus . 2013 . Hospice care http://www.nlm.nih.gov/medlineplus/endoflifeissues.html (accessed December 12, 2013)

Moeller, Phillip. 2013, February 26 . How to develop effective end-of-life plans . U.S. News Money http://money.usnews.com/money/blogs/the-best-life/2013/02/26/how-to-develop-effectiveend-of-life-plans(accessed December 13, 2013)

This is an Author's Accepted Manuscript of an Article published in Journal of Consumer Health on the Internet, June 4, 2014 and available online at: http://www.tandfonline.com/10.1080/15398285.2014.902285 ." 
National Cancer Institute . 2013 . Last days of Life (PDQ).

http://www.cancer.gov/cancertopics/pdq/supportivecare/lasthours/patient (accessed December 12, 2013)

National Institute on Aging . 2013 . End of life: Helping with comfort and care http://www.nia.nih.gov/health/publication/end-life-helping-comfort-and-care (printable version); http://www.cancer.org/acs/groups/cid/documents/webcontent/002899-pdf.pdf (accessed December 12, 2013)

NIHSeniorHealth. 2014. End of Life.

https://nihseniorhealth.gov/endoflife/preparingfortheendoflife/01.html(accessed April 11, 2014) 